\title{
Proteína Bruta e Energia Digestível em Dietas para Alevinos de Curimbatá (Prochilodus affins) ${ }^{1}$
}

\author{
Marcos Antonio Delmondes Bomfim ${ }^{2}$, Eduardo Arruda Teixeira Lanna ${ }^{3}$, Moacyr Antonio \\ Serafini ${ }^{4}$, Felipe Barbosa Ribeiro ${ }^{5}$, Karine da Silva Pena ${ }^{6}$
}

\begin{abstract}
RESUMO - Objetivando-se determinar as exigências de proteína bruta (PB) em função do nível de energia digestível (ED) da dieta para alevinos de curimbatá (Prochilodus affins), foram utilizados 256 peixes com peso inicial de 2,72 $\pm 0,11$ g, mantidos em 32 aquários de $100 \mathrm{~L}$, dotados de abastecimento de água, temperatura controlada e aeração individuais. O experimento foi realizado seguindo-se esquema fatorial 4 x 2 (quatro níveis de PB: 18,0;22,0;26,0; e 30,0\%, combinados com dois níveis de ED: 2.700 e 3.000 kcal $/ \mathrm{kg}$ ), em um delineamento inteiramente ao acaso, com quatro repetições e oito peixes por unidade experimental. Os peixes foram alimentados ad libitum em duas refeições diárias durante 78 dias. Avaliaram-se o ganho de peso, o consumo aparente de racão, a conversão alimentar aparente, a taxa de crescimento específico, a taxa de eficiência protéica, a eficiência de retenção de nitrogênio, a umidade, a proteína e a gordura corporais e as porcentagens de nitrogênio e de gordura no ganho de peso. Verificou-se que não houve interação dos níveis de $\mathrm{PB} \times \mathrm{ED}$, à exceção da porcentagem de gordura no ganho de peso. Com o nível de $3.000 \mathrm{kcal}$ de ED/kg, obtiveram-se peixes com maiores níveis de matéria seca, gordura corporal e porcentagem de gordura no ganho de peso. Concluiu-se que a exigência de PB e ED para alevinos de curimbatá é de $26,05 \%$ e $2.700 \mathrm{kcal} / \mathrm{kg}$, respectivamente, que corresponde a uma relação ED:PB de 10,36 kcal de ED/g de PB, por proporcionar as melhores respostas em ganho de peso e composição de carcaça.
\end{abstract}

Palavras-chave: curimbatá-pioa, exigências de energia e de proteína, nutrição de peixes, relação energia:proteína

\section{Crude Protein and Digestible Energy in the Diets for Curimbatá Fingerlings (Prochilodus affins)}

\begin{abstract}
Two hundred and fifty six curimbatá (Prochilodus affins) fingerlings averaging initial weight of $2.72 \pm 0.11 \mathrm{~g}$, stocked in 32 aquariums $(100 \mathrm{~L})$ with water renewal, controlled temperature and individual aeration, were used to determine the dietary crude protein (CP) requirements, according to the digestible energy level (DE). The experiment was carried out in to a $4 \mathrm{x} 2$ factorial scheme (four CP levels: 18.0, 22.0, 26.0 and 30.0\% combined with two DE levels: 2,700 and 3,000 kcal/kg), according to a completely randomized design with four replicates of eight fishes. The fishes were fed ad libitum twice a day, during 78 days. Weight gain, apparent feed intake, apparent feed:gain ratio, specific growth rate, protein efficiency rate, nitrogen retention efficiency, humidity, body fat and protein, nitrogen and fat percentage in weight gain were evaluated. No CP $\times$ DE levels interaction was observed for any studied variable, except for the fat percentage in weight gain. Fishes fed diets with 3,000 kcal de DE/kg showed higher levels of dry matter, body fat and fat percentage in weight gain. It was concluded that CP and DE requirements for curimbatá fingerlings are of $26.05 \%$ and $2,700 \mathrm{kcal} / \mathrm{kg}$, respectively, that correspond to DE:CP ratio of $10.36 \mathrm{kcal} \mathrm{DE} / \mathrm{g} \mathrm{CP}$, due to the best results of weight gain and carcass composition.
\end{abstract}

Key Words: curimbatá-pioa, energy:protein ratio, energy and protein requirements, fish nutrition

\section{Introdução}

Entre as espécies de peixe de interesse econômico-social, destaca-se a curimbatá (Prochilodus $s p$.), amplamente distribuída pela América Latina, cujos peixes têm o hábito alimentar limnófago ou iliófago(detritívoro), de baixonível trófico, alimentando-se no ambiente natural de material orgânico particulado (MOP), depositado no fundo ou na vegetação submergida, que, muitas vezes, é misturado com par- tículas minerais de baixo valor nutritivo. O MOP é constituído de vegetais mortos, ricos em lignina e celulose, além de pequenas quantidades de microinvertebrados vivos (algas, fungos e bactérias) (Boischio, 1992; Yossa \& Araujo-Lima, 1998; Furuya et al., 1999).

O curimbatá, entre os peixes nativos, é um dos que têm apresentado bom desempenho para a piscicultura, em virtude do rápido crescimento em cultivo intensivo, da alta rusticidade para manejo e da alta fertilidade,

\footnotetext{
1 Parte da tese de Mestrado do primeiro autor DZO/UFV - Viçosa-MG.

2 Engenheiro Agrônomo, Doutorando em Zootecnia - DZO/UFV. E.mail: madbomfim@hotmail.com

3 Professor do Departamento de Zootecnia - DZO/UFV. E.mail: elanna@ufv.br

${ }^{4}$ Professor da Escola Agrotécnica Federal de Santa Tereza - ES. E.mail: moacyraserafini@ig.com.br

${ }^{5}$ Mestrando em Zootecnia - DZO/UFV. E.mail: felipebribeiro@yahoo.com.br

${ }^{6}$ Estudante de graduação em Zootecnia DZO/UFV.
} 
estando entre as espécies de maior valor econômico aceitas para consumo humano no mercado nacional (Barbosa, 1987; Paixão \& Hancz, 1989; Cerdeira et al., 1997; Furuya et al., 1999; Galdioli et al., 2000; Galdioli et al., 2002). No entanto, tem sido uma das espécies mais afetadas pela poluição dos rios e pelas construções de represas hidroelétricas, com interferência no seu comportamento reprodutivo e, conseqüentemente, redução dos estoques pesqueiros (Barbosa, 1987; Pinto et al., 1984).

Apesar dessas características, ainda há carência de informações acerca de suas exigências nutricionais para que se possa desenvolver um programa nutricional adequado, a fim de possibilitar sua criação intensiva em condições econômicas. Ao contrário do ambiente natural, onde a diversidade e a disponibilidade dos alimentos permitem que os peixes equilibrem sua dieta, em ambientes confinados, sob condições de produção mais intensivas, os peixes dependem do arraçoamento e de dietas balanceadas, o que implica no conhecimento de exigências nutricionais para as diversas espécies.

A determinação das exigências nutricionais tem sido fundamental para elaboração de dietas com menor impacto ambiental e de baixo custo, principalmente daquelas utilizadas nos sistemas de produção de peixes com elevadas taxas de crescimento. Poucas pesquisas têm sido realizadas para determinação das exigências dietéticas de proteína bruta para o curimbatá e as existentes têm apresentado grande variabilidade entre os resultados. Têm-se observado resultados de 22 a $35 \%$ de $\mathrm{PB}$, o que pode estar relacionado ao nível de energia da dieta (Barbosa, 1987; Paixão \& Hancz, 1989; Furuya et al., 1999).

Portanto, verifica-se a necessidade de se determinar a exigência de proteína bruta, em função do teor de energia digestível nas dietas para alevinos de curimbatá, visando otimizar seu desempenho e qualidade de carcaça.

\section{Material e Métodos}

O experimento foi conduzido no período de 08 de julho a 24 de setembro de 2002 no Laboratório de Nutrição de Peixes do Departamento de Zootecnia da Universidade Federal de Viçosa (UFV), localizado no município de Viçosa, Minas Gerais.

Duzentos e cinqüenta e seis alevivos de curimbatá (Prochilodus affinis), com peso inicial de 2,72 $\pm 0,11 \mathrm{~g}$, obtidos de mesma desova induzida, foram utilizados no experimento, montado em esquema fatorial $4 \times 2$ (quatro níveis protéicos e dois níveis energéticos), em um delineamento inteiramente casualizado, com quatro repetições por tratamento e oito peixes por unidade experimental.

Foram formuladas oito rações experimentais, contendo quatro níveis de proteína bruta $(18,0 ; 22,0 ; 26,0$; e 30,0\% de PB), combinados com dois níveis de energia (2.700 e $3.000 \mathrm{kcal} / \mathrm{kg}$ de energia digestível), caracterizando os seguintes tratamentos: 18-27 = $18,0 \%$ de $\mathrm{PB}$ e $2.700 \mathrm{kcal} \mathrm{de} \mathrm{ED} / \mathrm{kg} ; 18-30=18,0 \%$ de $\mathrm{PB}$ e $3.000 \mathrm{kcal}$ de $\mathrm{ED} / \mathrm{kg} ; 22-27=22,0 \%$ de $\mathrm{PB}$ e $2.700 \mathrm{kcal}$ de $\mathrm{ED} / \mathrm{kg} ; 22-30=22,0 \%$ de $\mathrm{PB}$ e 3.000 $\mathrm{kcal}$ de ED $/ \mathrm{kg} ; 26-27=26,0 \%$ de $\mathrm{PB}$ e $2.700 \mathrm{kcal} \mathrm{de}$ $\mathrm{ED} / \mathrm{kg}$ ); $26-30=26,0 \%$ de $\mathrm{PB}$ e $3.000 \mathrm{kcal}$ de $\mathrm{ED} / \mathrm{kg}$; $30-27=30,0 \%$ de $\mathrm{PB}$ e $2.700 \mathrm{kcal} \mathrm{de} \mathrm{ED} / \mathrm{kg}$; e $30-30$ $=30,0 \%$ de $\mathrm{PB}$ e $3.000 \mathrm{kcal}$ de $\mathrm{ED} / \mathrm{kg}$.

A composição das dietas experimentais pode ser visualizada na Tabela 1 .

Foram utilizados 32 aquários de cimento-amianto, com capacidade volumétrica de $100 \mathrm{~L}$, dotados de sistemas individuais de abastecimento de água, aeração e escoamento de fundo.

A água de abastecimento dos aquários, proveniente do sistema de tratamento de água da Universidade Federal de Viçosa - UFV, foi previamente tratada com anticloro e aquecida por resistências elétricas, com temperatura controlada por termostato. A temperatura da água foi aferida diariamente, às 8 e 17 h, com o auxílio de termômetro de bulbo de mercúrio, graduado de 0 a $50^{\circ} \mathrm{C}$.

Os controles do $\mathrm{pH}$ e do teor de oxigênio dissolvido na água foram efetuados a cada 7 dias, respectivamente, por intemédio de um potenciômetro (DIGIMED modelo DMPH-PV) e de um oxímetro (DIGIMED modelo DMO-2). O fotoperíodo foi mantido em 12 horas de luz, por meio de iluminação proveniente de lâmpadas mistas, controladas por timer automático.

As dietas experimentais foram peletizadas e oferecidas ad libitum diariamente, em duas refeições (8 e 17 h), em uma quantidade que possibilitou a ingestão máxima sem que houvesse perdas. Foi realizada a limpeza diária dos aquários após a leitura matinal da temperatura da água, por sifonagem, para retirada das fezes eventuais sobras de ração.

Foram avaliados os seguintes índices de desempenho zootécnico: ganho de peso (GP), consumo aparente de ração (CAR), conversão alimentar aparente (CAA), taxa de crescimento específico (TCE) e taxa 
Tabela 1 - Composições percentual e química das dietas experimentais (matéria natural)

Table 1 - Chemical composition (\%) of the experimental diets (as-fed basis)

\begin{tabular}{|c|c|c|c|c|c|c|c|c|}
\hline \multirow[t]{2}{*}{$\begin{array}{l}\text { Ingrediente }(\%) \\
\text { Ingredient (\%) }\end{array}$} & \multicolumn{8}{|c|}{$\begin{array}{l}\text { Dieta } \\
\text { Diet }\end{array}$} \\
\hline & R 18-27 & R 18-30 & R $22-27$ & $\mathrm{R} 22-30$ & $\mathrm{R} 26-27$ & R26-30 & R $30-27$ & R30-30 \\
\hline $\begin{array}{l}\text { Farelo de soja } \\
\text { Soybean meal }\end{array}$ & 25,09 & 26,25 & 37,27 & 37,46 & 50,51 & 48,56 & 63,47 & 59,54 \\
\hline $\begin{array}{l}\text { Fubá de milho } \\
\text { Corn meal }\end{array}$ & 55,33 & 48,76 & 41,15 & 40,60 & 20,10 & 32,47 & 0,00 & 24,39 \\
\hline $\begin{array}{l}\text { Feno de alfafa } \\
\text { Dehydrated alfalfa meal }\end{array}$ & 9,91 & 10,12 & 8,00 & 7,99 & 6,32 & 5,90 & 4,65 & 3,82 \\
\hline $\begin{array}{l}\text { Amido de milho } \\
\text { Corn starch }\end{array}$ & 5,00 & 5,00 & 9,46 & 5,00 & 19,00 & 5,00 & 27,86 & 5,00 \\
\hline $\begin{array}{l}\text { Óleo de soja } \\
\text { Soybean oil }\end{array}$ & 0,41 & 5,62 & 0,00 & 4,84 & 0,00 & 4,05 & 0,00 & 3,25 \\
\hline $\begin{array}{l}\text { Fosfato bicálcico } \\
\text { Dicalcium phosphate }\end{array}$ & 2,69 & 2,73 & 2,51 & 2,51 & 2,38 & 2,28 & 2,26 & 2,06 \\
\hline $\begin{array}{l}\text { Calcário calcítico } \\
\text { Limestone }\end{array}$ & 0,26 & 0,22 & 0,35 & 0,35 & 0,44 & 0,49 & 0,45 & 0,62 \\
\hline $\begin{array}{l}\text { DL-metionina } \\
\text { DL-methionine }\end{array}$ & 0,02 & 0,03 & 0,04 & 0,04 & 0,10 & 0,06 & 0,16 & 0,11 \\
\hline $\begin{array}{l}\text { L-Lisina } \mathrm{HCl} \\
\text { L-Lysine } \mathrm{HCl}\end{array}$ & 0,14 & 0,12 & 0,07 & 0,06 & 0,00 & 0,04 & 0,00 & 0,06 \\
\hline $\begin{array}{l}\text { Suplemento vitamínico e mineral } \\
\text { Vitamin and mineral mix }\end{array}$ & 0,60 & 0,60 & 0,60 & 0,60 & 0,60 & 0,60 & 0,60 & 0,60 \\
\hline $\begin{array}{l}\text { Vitamina C } \\
\text { Vitamin } C\end{array}$ & 0,03 & 0,03 & 0,03 & 0,03 & 0,03 & 0,03 & 0,03 & 0,03 \\
\hline $\begin{array}{l}\text { Sal comum } \\
\text { Salt }\end{array}$ & 0,50 & 0,50 & 0,50 & 0,50 & 0,50 & 0,50 & 0,50 & 0,50 \\
\hline $\begin{array}{l}\text { BHT (Antioxidante) } \\
\text { BHT (Antioxidant) }\end{array}$ & 0,02 & 0,02 & 0,02 & 0,02 & 0,02 & 0,02 & 0,02 & 0,02 \\
\hline \multicolumn{9}{|l|}{$\begin{array}{l}\text { Composição calculada } \\
\text { Calculated composition }\end{array}$} \\
\hline $\begin{array}{l}\text { Proteína bruta, } \% 1 \\
\text { Crude protein, } \%\end{array}$ & 18,00 & 18,00 & 22,00 & 22,00 & 26,00 & 26,00 & 30,00 & 30,00 \\
\hline $\begin{array}{l}\text { Extrato etéreo, } \%{ }^{1} \\
\text { Ether extract, } \%\end{array}$ & 3,08 & 8,09 & 2,37 & 7,20 & 1,86 & 6,30 & 1,38 & 5,38 \\
\hline $\begin{array}{l}\text { Fibra bruta, } \%^{1} \\
\text { Crude fiber, } \%\end{array}$ & 5,00 & 5,00 & 5,00 & 5,00 & 5,00 & 5,00 & 5,00 & 5,00 \\
\hline $\begin{array}{l}\text { Energia digestível, } \mathrm{kcal} / \mathrm{kg}^{2} \\
\text { Digestible energy, } \mathrm{kcal} / \mathrm{kg}\end{array}$ & 2.700 & 3.000 & 2.700 & 3.000 & 2.700 & 3.000 & 2.700 & 3.000 \\
\hline $\begin{array}{l}\text { Cálcio total } \\
\text { Total calcium, } \%\end{array}$ & 1,00 & 1,00 & 1,00 & 1,00 & 1,00 & 1,00 & 1,00 & 1,00 \\
\hline $\begin{array}{l}\text { Fósforo total }{ }^{2} \\
\text { Total phosphorus, } \%\end{array}$ & 0,80 & 0,80 & 0,80 & 0,80 & 0,80 & 0,80 & 0,80 & 0,80 \\
\hline $\begin{array}{l}\text { Metionina + cistina } \\
\text { Methionine }+ \text { cystine }\end{array}$ & 0,59 & 0,59 & 0,69 & 0,69 & 0,81 & 0,81 & 0,93 & 0,93 \\
\hline $\begin{array}{l}\text { Lisina }^{2} \\
\text { Lysine }\end{array}$ & 1,03 & 1,03 & 1,26 & 1,26 & 1,51 & 1,51 & 1,80 & 1,80 \\
\hline $\begin{array}{l}\text { Relação ED:PB } \\
D E: C P \text { ratio }\end{array}$ & 15,00 & 16,67 & 12,27 & 13,64 & 10,38 & 11,54 & 9,00 & 10,00 \\
\hline
\end{tabular}

1 Com base nas análises de laboratório LNA/DZO (Samples were analyzed at - LNA/DZO).

2 Com base nos valores propostos pelo NRC (1983), pelo NRC (1993) e por Rostagno et al. (2000).

2 Based on the NRC (1983), NRC (1993) and Rostagno et al. (2000) data.

${ }^{3}$ Suplemento vitamínico comercial (vitamin mix) (5 kg/t), com níveis de garantia por quilograma do produto: Vit. A, 1.200.000 UI; Vit. $D_{3}, 200.000$ UI; Vit. E, 12.000 mg; Vit. $K_{3}, 2.400$ mg; Vit. $B_{1}, 4.800$ mg; Vit. $B_{2}, 4.800$ mg; Vit. $B_{6}, 4.000$ mg; Vit. $B_{12}, 4.800$ mg; ác. fólico (folic acid), $1.200 \mathrm{mg}$; pantotenato de Ca (Ca pantotenate), $12.000 \mathrm{mg}$; Vit. C, $48.000 \mathrm{mg}$; biotina (biotin), $48 \mathrm{mg}$; cloreto de colina (choline), $108.000 \mathrm{mg}$ niacina (niacin), $24.000 \mathrm{mg}$; e suplemento mineral comercial (mineral mix) (1 kg/t), com níveis de garantia por quilograma do produto: Fe, 50.000 mg; Cu, 3.000 mg; Mn, 20.000 mg; Zn, 3.000 mg; I, 100 mg; Co, 10 mg; Se, 100 mg. 
de eficiência protéica (TEP). Foram avaliadas ainda as seguintes características: composição química corporal (teores de umidade, proteína e gordura corporais), porcentagem de nitrogênio no ganho de peso (NGP), porcentagem de gordura no ganho de peso (GGP) e eficiência de retenção de nitrogênio (ERN).

Para avaliação do desempenho, os peixes foram pesados, em grupo por unidade experimental, após jejum de 24 horas no início e no final do experimento. O GP foi obtido pela diferença de peso entre os pesos médios final e inicial. Para determinação da TCE, foi adotada a equação abaixo, utilizando-se transformações logarítmicas:

$$
\mathrm{TCE}=\frac{\log \text { peso final }(\mathrm{g})-\log \text { peso inicial }(\mathrm{g})}{\text { tempo de experimento }(\text { dias })} \times 100
$$

A CAA foi calculada dividindo-se o consumo aparente de ração pelo ganho de peso dos peixes. A TEP foi obtida pela divisão entre o ganho de peso dos peixes e o consumo de proteína bruta.

Para as análises corporais, os curimbatás foram insensibilizados e sacrificados com gelo, e congelados no início ( $20 \%$ da quantidade de peixes utilizados no experimento) e no final do experimento (quatro peixes por unidade experimental, com pesos correspondentes ao peso médio da respectiva unidade). Esses peixes foram utilizados para determinação da ERN, da NGP, da GGP e da composição química corporal. A ERN, expressa em porcentagem, foi calculada pela diferença do nitrogênio corporal final e inicial, dividido pelo nitrogênio total consumido, multiplicado por 100. A NGP e a GGP foram calculadas pela diferença de nitrogênio e gorduras corporais final e inicial, respectivamente, dividida pelo ganho de peso, multiplicada por 100 .

As análises dos ingredientes utilizados nas dietas e das amostras dos peixes foram realizadas no Laboratório de Nutrição Animal do Departamento de Zootecnia (LNA/DZO) da Universidade Federal de Viçosa - UFV, conforme procedimentos descritos por Silva (1998).

As análises estatísticas foram realizadas pelo programa SAEG - Sistema de Análises Estatísticas e Genéticas. Os dados foram interpretados por meio de análises de variância e regressão a $5 \%$ de probabilidade e os efeitos dos níveis de energia digestível foram comparados pelo teste F. Os efeitos dos níveis de proteína bruta foram analisados mediante o uso dos modelos de regressão linear, quadrático ou descontínuo "Linear Response Plateau" (LRP), conforme o melhor ajustamento obtido para cada variável, com base na significância dos coeficientes de regressão pelo teste F, no coeficiente de determinação, na soma de quadrado dos desvios e no fenômeno em estudo.

\section{Resultados e Discussão}

O sistema de abastecimento de água e de aeração possibilitou a manutenção da temperatura e da aeração uniformes durante o período experimental. Foram obtidos os valores de $26,0 \pm 0,76^{\circ} \mathrm{C}$ para temperatura da água, de 6,8 $\pm 0,16$ para o $\mathrm{pH}$ e de $6,9 \pm 0,1 \mathrm{ppm}$ (ou mg/L) para o oxigênio dissolvido. Valores similares a estes foram citados por Furuya et al. (1999), Galdioli et al. (2000) e Galdioli et al. (2002) como ideais para o cultivo de curimbatás.

Os resultados médios do ganho de peso (GP), da taxa de crescimento específico (TCE), do consumo aparente de ração (CAR), da conversão alimentar aparente de ração (CAA) e da taxa de eficiência protéica (TEP) encontram-se na Tabela 2.

O GP dos peixes foi aquém do esperado, o que pode ter sido conseqüência do estresse apresentado, em razão do manejo intensivo durante o período experimental. Embora não tenha sido observada interação dos níveis de proteína bruta $(\mathrm{PB}) \times$ energia digestível (ED) $(\mathrm{P}>0,05)$ e ainda que não tenha sido influenciado pelos níveis energéticos $(\mathrm{P}>0,05)$ da dieta, o ganho de peso, mesmo a baixos valores, foi suficiente para ser afetado pela variação dos níveis de proteína bruta da dieta, uma vez que as diferenças foram estatisticamente distintas em nível altamente significativo $(\mathrm{P}<0,01)$, aumentando linearmente à medida que se elevaram os níveis de $\mathrm{PB}$ na dieta. Apesar da variação linear, o modelo "Linear Response Plateau" - LRP foi o que melhor se ajustou aos dados, estimando em 26,05\% o nível de PB a partir do qual ocorreu um platô em 3,41 g. A representação gráfica deste efeito pode ser visualizada na Figura 1.

Este resultado foi semelhante aos obtidos por Brenner (1988), com pacu, e por Sá \& Fracalossi (2002), com piracanjuba, que verificaram aumento linear de ganho de peso dos animais, com a ocorrência de platô a partir de um dos níveis intermediários de $\mathrm{PB}$ avaliados. No entanto, diferiram aos obtidos por Vidal Jr. (1995), com tambaqui, por Santiago \& Reyes (1991), com carpa cabeça grande, por Siddiqui et al. 
(1988), Furuya et al. (1996) e Furuya et al. (2000), com tilápia, e por Hayashi et al. (1999), com lambari, os quais verificaram aumento de ganho de peso limitado a determinado nível protéico, com decréscimo nos níveis subseqüentes.

Esta diferença pode estar relacionada ao nível de carboidratos nas dietas. Segundo Cowey \& Walton (1989), quando os peixes são alimentados com dietas contendo maior relação proteína:carboidrato, há elevação dos níveis hepáticos de enzimas gliconeogênicas
(PEP carboxiquinase e frutose bifosfatase) e diminuição das glicolíticas (fosfofrutoquinase, piruvato quinase e lactato desidrogenase); o contrário é observado em dietas com menor relação proteína:carboidrato, porém com pequeno efeito na atividade das enzimas envolvidas com o catabolismo dos aminoácidos, o que pode indicar que, na dieta contendo $30 \%$ de PB e $3.000 \mathrm{kcal} \mathrm{de} \mathrm{ED} / \mathrm{kg}$, a qual possui maiores relações proteína:carboidrato e ED:PB, quando comparada à dieta contendo $30 \%$ de $\mathrm{PB}$ e $2.700 \mathrm{kcal}$ de $\mathrm{ED} / \mathrm{kg}$, o

Tabela 2 - Ganho de peso (GP), taxa de crescimento específico (TCE), consumo aparente de ração (CAR), conversão alimentar aparente (CAA), taxa de eficiência protéica (TEP) de alevinos de curimbatá e resumo da análise de variância, em função dos níveis de proteína bruta (PB) e de energia digestível (ED)

Table 2 - Weight gain (WG), specific growth rate (SGR), apparent feed intake (ADC), apparent feed/gain ratio (FCR), and protein efficiency rate (PER) of curimbatá fingerlings and summary of the analysis of variance, according to different crude protein $(C P)$ and digestible energy (DE) levels

\begin{tabular}{|c|c|c|c|c|c|c|c|c|c|c|c|}
\hline \multirow[t]{2}{*}{$\begin{array}{l}\mathrm{PB}(\%) \\
C P(\%)\end{array}$} & \multirow[t]{2}{*}{$\begin{array}{l}\mathrm{ED}(\mathrm{kcal} / \mathrm{kg}) \\
D E(\text { ccal } / \mathrm{kg})\end{array}$} & \multicolumn{2}{|c|}{$\begin{array}{c}\mathrm{GP}^{1}(\mathrm{~g}) \\
W G\end{array}$} & \multicolumn{2}{|c|}{$\begin{array}{l}\mathrm{TCE}^{2} \\
S G R\end{array}$} & \multicolumn{2}{|c|}{$\begin{array}{c}\mathrm{CAR}^{3}(\mathrm{~g}) \\
A D C\end{array}$} & \multicolumn{2}{|c|}{$\begin{array}{c}\mathrm{CAA}^{4} \\
F C R\end{array}$} & \multicolumn{2}{|c|}{$\begin{array}{l}\text { TEP }^{5} \\
P E R\end{array}$} \\
\hline & & & $\begin{array}{l}\text { Média } \\
\text { Mean }\end{array}$ & & $\begin{array}{l}\text { Média } \\
\text { Mean }\end{array}$ & & $\begin{array}{l}\text { Média } \\
\text { Mean }\end{array}$ & & $\begin{array}{l}\text { Média } \\
\text { Mean }\end{array}$ & & $\begin{array}{l}\text { Média } \\
\text { Mean }\end{array}$ \\
\hline \multirow{2}{*}{18} & 2.700 & 1,96 & \multirow{2}{*}{1,81} & 0,30 & \multirow[t]{2}{*}{0,28} & 8,05 & \multirow[t]{2}{*}{7,61} & 4,20 & \multirow[t]{2}{*}{4,29} & 1,36 & \multirow[t]{2}{*}{1,33} \\
\hline & 3.000 & 1,66 & & 0,27 & & 7,17 & & 4,37 & & 1,30 & \\
\hline \multirow[t]{2}{*}{22} & 2.700 & 2,36 & 2,35 & 0,35 & \multirow[t]{2}{*}{0,34} & 7,70 & 7,97 & 3,35 & \multirow[t]{2}{*}{3,49} & 1,37 & \multirow[t]{2}{*}{1,33} \\
\hline & 3.000 & 2,33 & & 0,34 & & 8,25 & & 3,64 & & 1,28 & \\
\hline \multirow[t]{2}{*}{26} & 2.700 & 3,47 & 3,50 & 0,46 & \multirow[t]{2}{*}{0,46} & 9,34 & 9,19 & 2,68 & \multirow[t]{2}{*}{2,63} & 1,45 & \multirow[t]{2}{*}{1,48} \\
\hline & 3.000 & 3,54 & & 0,46 & & 9,04 & & 2,58 & & 1,50 & \\
\hline \multirow[t]{2}{*}{30} & 2.700 & 3,71 & 3,32 & 0,48 & \multirow[t]{2}{*}{0,44} & 10,13 & 9,97 & 2,73 & \multirow[t]{2}{*}{3,05} & 1,24 & \multirow[t]{2}{*}{1,12} \\
\hline & 3.000 & 2,92 & & 0,41 & & 9,82 & & 3,36 & & 1,00 & \\
\hline \multirow{2}{*}{$\begin{array}{l}\text { Média } \\
\text { Mean }\end{array}$} & 2.700 & \multicolumn{2}{|c|}{2,88} & \multicolumn{2}{|c|}{0,39} & \multicolumn{2}{|c|}{8,80} & \multicolumn{2}{|c|}{3,24} & \multicolumn{2}{|c|}{1,35} \\
\hline & 3.000 & \multicolumn{2}{|c|}{2,61} & \multicolumn{2}{|c|}{0,37} & \multicolumn{2}{|c|}{8,57} & \multicolumn{2}{|c|}{3,49} & &, 27 \\
\hline $\begin{array}{l}\text { Nível de } \\
\text { CPlevel }\end{array}$ & & $* *$ & & & & & & & $* *$ & & * \\
\hline $\begin{array}{l}\text { Nível de } \\
\text { DE level }\end{array}$ & & $\mathrm{N}$ & & & & & & & NS & & NS \\
\hline $\begin{array}{l}\text { Interaçã } \\
\text { Interacti }\end{array}$ & $\begin{array}{l}\mathrm{PB} \times \mathrm{ED} \\
C P \times D E\end{array}$ & $\mathrm{~N}$ & & & & & & & NS & & NS \\
\hline CV (\%) & & 21,4 & & & & & & & 17 & & ,67 \\
\hline
\end{tabular}

CV - coeficiente de variação (coefficient of variation).

${ }^{*}(\mathrm{P}<0,05),{ }^{* *}(\mathrm{P}<0,01)$ e ns $(\mathrm{P}>0,05)$, pelo teste $\mathrm{F}\left[{ }^{*}(P<0.05),{ }^{* *}(P<0.01)\right.$ and $n s(P>0.05)$, by $F$ test $]$.

1 Efeito LRP (Linear Response Plateau effect): $\hat{Y}=-2,1113+0,2120 X\left(r^{2}=0,96\right)$; platô (plateau) $v=3,41$.

2 Efeito LRP (Linear Response Plateau effect): $\hat{Y}=0,1202+0,0219 X\left(r^{2}=0,97\right)$; platô (plateau) v= 0,45.

3 Efeito linear (Linear effect): $\hat{Y}=3,7080+0,2074 X\left(r^{2}=0,96\right)$.

4 Efeito quadrático (Quadractic effect): $\hat{Y}=16,6353-1,0229 X+0,01893 X^{2}\left(R^{2}=0,94\right)$.

${ }^{5}$ Efeito quadrático (Quadractic effect): $\hat{Y}=-1,4579+0,2522 X+0,00551 X^{2}\left(R^{2}=0,66\right)$. 


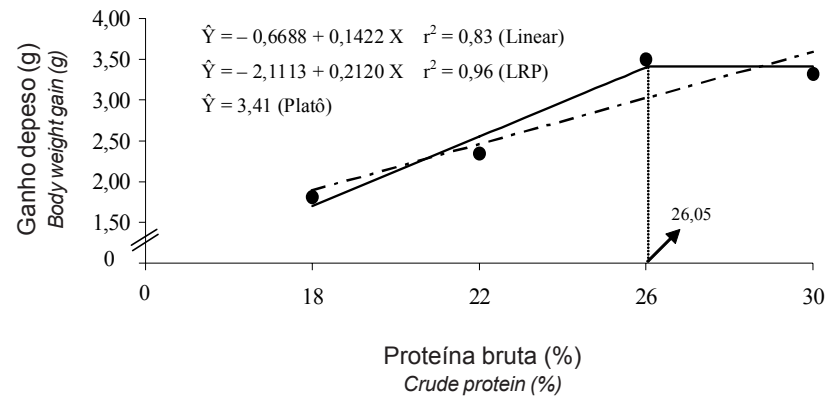

Figura 1 - Representação gráfica do ganho de peso de alevinos de curimbatá, em função do nível protéico da dieta.

Figure 1 - Body weight gain of curimbatá fingerlings fed different protein levels.

nível carboidrato parece ter sido o limitante para o crescimento, em vez do nível de proteína ou de energia. Desse modo, parte significativa da proteína pode ter sido utilizada na rota gliconeogênica, influenciando o menor ganho de peso obtido para o referido nível energético.

Por outro lado, para a dieta com $30 \%$ de PB e 2.700 $\mathrm{kcal}$ de ED/kg, embora de menor relação ED:PB, o nível de energia, assim como o de carboidrato (menor relação proteína:carboidrato), demonstrou não ter limitado o GP. Neste caso, o maior teor de carboidrato da dieta minimizou a utilização excessiva dos aminoácidos na via gliconeogênica, poupando-os para serem utilizados para a deposição protéica, uma vez que, em ambos os casos, a excreção dos resíduos nitrogenados é feita principalmente na forma de amônia, por difusão passiva com baixo gasto calórico (Cowey \& Walton, 1989). Torna-se necessária, todavia, a realização de mais estudos utilizando maior amplitude de níveis de PB, para validação dessas hipóteses.

De forma semelhante ao GP, para a TCE também não houve interação dos níveis de $\mathrm{PB} \times \mathrm{ED}(\mathrm{P}>0,05)$, nem influência dos níveis energéticos $(\mathrm{P}>0,05)$ sobre esta variável. Entretanto, foi verificado aumento $(\mathrm{P}<0,01)$ da TCE de forma linear, à medida que se elevaram os níveis de PB na dieta. Apesar da variação linear, o modelo "Linear Response Plateau" LRP foi o que melhor se ajustou aos dados, estimando em $26,01 \%$ o nível de PB, a partir do qual ocorreu um platô em 0,45 de TCE.

Comportamento análogo foi verificado por Brenner (1988), com pacus, e por El-Sayed \& Teshima (1992), com tilápias. Entretanto, esta tendência difere dos resultados obtidos por Siddiqui et al. (1988), que verificaram aumento da TCE limitado a determinado nível protéico, com decréscimo nos níveis subseqüentes.

Apesar da carência de informações a respeito das taxas de crescimento desta espécie de curimbatá em condições intensivas, em que a alimentação se baseia apenas na alimentação artificial, outros pesquisadores (Paixão, 1988, híbridos Prochlilodus marggravii x Prochlilodus affinis; Leite et al., 1984 e Pinto et al., 1984, Prochlilodus scrofa; Galdioli et al., 2000, Prochlilodus lineatus V.; Paixão \& Hancz, 1989, Prochlilodus marggravii), embora tenham trabalhado com faixas de peso distintas, também observaram baixas taxas de crescimento específico, com valores variando de insignificante (não apresentados), mas estatisticamente diferente entre os pesos final e inicial, a 0,$55 ; 0,50 ; 1,22$ e $1,23 \%$ ao dia, respectivamente (dados calculados).

Contudo, Pinto et al. (1984), Leite et al. (1994) e Paixão \& Hancz (1989) verificaram que a associação entre a adubação orgânica e a suplementação alimentar com ração resultou em efeito positivo no crescimento dos peixes, nas condições de confinamento, em relação àqueles criados em viveiros apenas adubados, demonstrando a necessidade da formulação de dietas balanceadas que maximizem sua produtividade em sistemas menos intensificados.

Não se observou interação dos níveis de $\mathrm{PB} \times \mathrm{ED}$ $(\mathrm{P}>0,05)$, nem influência dos níveis de energia $(\mathrm{P}>0,05)$ sobre o CRA. Estes resultados parecem contrariar a tendência de que os peixes se alimentam para satisfazer primariamente suas exigências em energia (Page \& Andrews, 1973; Lee \& Putnam, 1973; El-Dahhar \& Lovell, 1995; Sampaio et al., 2000). No entanto, corroboram a teoria de Winfree \& Stickney (1984) de que, aparentemente, dentro de determinados limites, os peixes podem satisfazer suas exigências em proteína pela variação do consumo.

No entanto, foi observado aumento linear no CRA $(\mathrm{P}<0,01)$ de acordo com a elevação dos níveis de $\mathrm{PB}$, o que pode ser atribuído às maiores taxas de crescimento obtidas pelos peixes alimentados com as dietas contendo níveis protéicos mais elevados (El-Dahhar \& Lovell, 1995).

Também não foi observada interação dos níveis protéicos $\times$ energéticos da ração $(\mathrm{P}>0,05)$ sobre a CAA, que não variou em função dos níveis de $\mathrm{ED}$ $(\mathrm{P}>0,05)$. Porém, houve efeito quadrático $(\mathrm{P}<0,01)$ dos níveis de $\mathrm{PB}$ sobre a $\mathrm{CAA}$, que apresentou valor 
mínimo de 2,8, melhorando até o nível estimado de $27,03 \%$ de PB (Figura 2).

Variação quadrática da CAA dos peixes, em razão do aumento do nível de proteína da dieta, semelhante à verificada neste estudo, também foi observada por diferentes autores (Siddiqui et al., 1988; Santiago \& Reyes, 1991; Furuya et al., 2000; Sá \& Fracalossi, 2002).

Em algumas pesquisas, no entanto, foram verificados casos em que houve melhoria de forma linear na CAA, quando se elevou o teor de PB ou reduziu a relação ED/PB da dieta (El-Dahhar \& Lovell, 1995; Fernandes et al., 2000; Sampaio et al., 2000; Pezzato et al., 2000), assim como foram verificados casos em que a variação dos níveis protéicos não afetou a CAA (Vidal Jr., 1995; Furuya et al., 1996).

Não foi observada interação dos níveis de $\mathrm{PB} \times \mathrm{ED}$ $(\mathrm{P}>0,05)$ sobre a TEP, que não foi influenciada pelos níveis de $\mathrm{ED}(\mathrm{P}>0,05)$. Contudo, a elevação dos níveis de $\mathrm{PB}$ influenciou $(\mathrm{P}<0,05)$ de forma quadrática esta variável, que melhorou até o nível estimado de 22,89\% de PB, com valor máximo de 1,38 de TEP.

Os valores médios da eficiência de retenção de nitrogênio (ERN), da porcentagem de nitrogênio no ganho de peso (NGP) e da porcentagem de gordura no ganho de peso (GGP) estão apresentados na Tabela 3.

Não houve interação dos níveis de $\mathrm{PB} \times$ de ED $(\mathrm{P}>0,05)$ sobre a ERN, que também não foi influenciada pelos níveis de $\mathrm{ED}(\mathrm{P}>0,05)$ na ração. Contudo, a elevação dos níveis de $\mathrm{PB}$ na dieta influenciou $(\mathrm{P}<0,05)$ de forma quadrática a $\mathrm{ERN}$, que melhorou até o nível estimado de $25,44 \%$ de $\mathrm{PB}$, com valor máximo de 16,48\% (Figura 3).

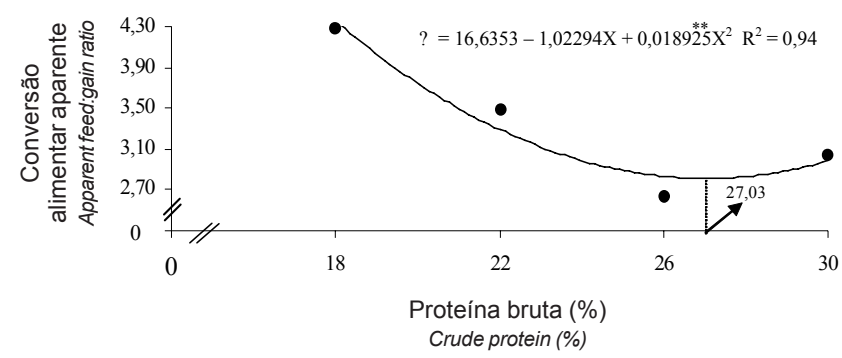

Figura 2 - Representação gráfica da conversão alimentar aparente de alevinos de curimbatá, em função do nível protéico da dieta.

Figure 2 - Apparent feed/gain ratio, according to different dietary protein levels fed to curimbatá fingerlings.
Segundo Sampaio et al. (2000), existe uma relação entre o nível de proteína da dieta e sua utilização pelo peixe. Esta relação pode ser descrita como a seguir: quando a dieta apresenta baixos níveis de proteína, a eficiência na utilização de proteína é baixa; à medida que o nível de proteína aumenta, a utilização de proteína também melhora e alcança o máximo perto do nível mínimo de proteína exigido; em níveis de proteína além do mínimo exigido, a eficiência de na utilização de proteína diminui.

Assim, o nível de PB estimado para o máximo ganho de peso pode estar fornecendo excesso desse nutriente, reduzindo a eficiência de sua utilização, uma vez que parte não é utilizada para síntese protéica e, dessa forma, o valor máximo de retenção pode estar sempre abaixo do nível encontrado para o máximo ganho de peso (Bowen, 1987, citado por Furuya et al., 2000).

Neste estudo, nos peixes alimentados com dietas contendo níveis de PB inferiores a 25,44\%, a proteína ingerida pode ter sido insuficiente para atender a exigência mínima em aminoácidos para mantença (turnover protéico) e máxima deposição protéica. Para os níveis superiores, parte da proteína pode ter sido catabolizada para fins energéticos, lipogênese ou gliconeogênese, que, em ambos os casos, diminui a ERN. Esta tendência se assemelha à obtida para a TEP, embora tenha apresentado valores para eficiência máxima distintos.

Além disso, os peixes alimentados com as dietas contendo menor concentração energética tenderam a apresentar maior CRA e a proteína consumida foi eficientemente transformada em proteína corporal, o que pode ter refletido em melhores

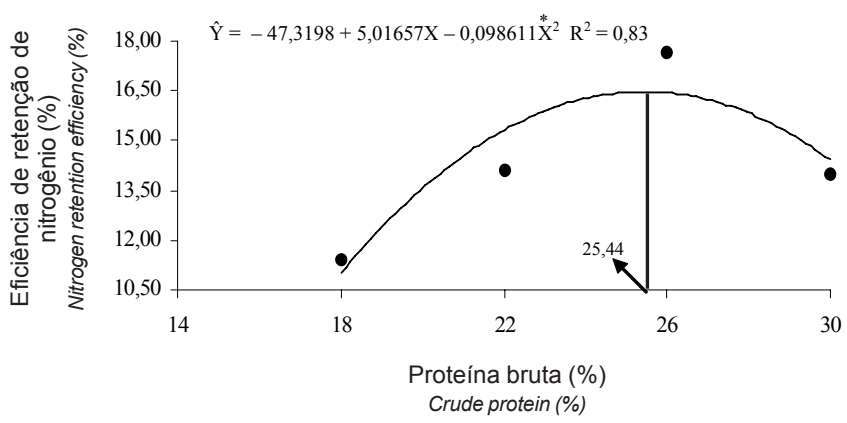

Figura 3 - Representação gráfica da eficiência de retenção de nitrogênio de alevinos de curimbatá, em função do nível protéico da dieta.

Figure 3 - Nitrogen retention efficiency of curimbatá fingerlings fed different protein levels. 
Tabela 3 - Eficiência de retenção de nitrogênio (ERN), porcentagem de nitrogênio no ganho de peso (NGP), porcentagem de gordura no ganho de peso (GGP) de alevinos de curimbatá e resumo da análise de variância, em função do nível de proteína bruta (PB) e de energia digestível (ED)

Table 3 - Nitrogen retention efficiency (NRE), nitrogen percentage in weight gain (NWG), fat percentage on weight gain (FWG) and summary of the analysis of variance, according to different crude protein $(C P)$ and digestible energy (DE) levels fed to curimbatá fingerlings

\begin{tabular}{|c|c|c|c|c|c|c|c|}
\hline \multirow[t]{2}{*}{$\begin{array}{l}\mathrm{PB}(\%) \\
C P(\%)\end{array}$} & \multirow[t]{2}{*}{$\begin{array}{l}\mathrm{ED}(\mathrm{kcal} / \mathrm{kg}) \\
D E(\text { kcal } / \mathrm{kg})\end{array}$} & \multicolumn{2}{|c|}{$\begin{array}{l}\operatorname{ERN}^{1}(\%) \\
N R E(\%)\end{array}$} & \multicolumn{2}{|c|}{$\begin{array}{l}\mathrm{NGP}^{2}(\%) \\
N W G(\%)\end{array}$} & \multicolumn{2}{|c|}{$\begin{array}{l}\mathrm{GGP}^{3}(\%) \\
F W G(\%)\end{array}$} \\
\hline & & & $\begin{array}{l}\text { Média } \\
\text { Mean }\end{array}$ & & $\begin{array}{l}\text { Média } \\
\text { Mean }\end{array}$ & & $\begin{array}{l}\text { Média } \\
\text { Mean }\end{array}$ \\
\hline \multirow[t]{2}{*}{18} & 2.700 & 12,45 & \multirow{2}{*}{11,44} & 1,37 & \multirow{2}{*}{1,29} & 5,99 & \multirow{2}{*}{8,25} \\
\hline & 3.000 & 10,43 & & 1,21 & & 10,50 & \\
\hline \multirow[t]{2}{*}{22} & 2.700 & 14,77 & \multirow{2}{*}{14,08} & 1,6 & \multirow{2}{*}{1,63} & 4,94 & \multirow{2}{*}{6,87} \\
\hline & 3.000 & 13,40 & & 1,61 & & 8,80 & \\
\hline \multirow[t]{2}{*}{26} & 2.700 & 17,81 & \multirow{2}{*}{17,69} & 1,93 & \multirow{2}{*}{1,88} & 3,36 & \multirow{2}{*}{4,58} \\
\hline & 3.000 & 17,56 & & 1,82 & & 5,80 & \\
\hline \multirow[t]{2}{*}{30} & 2.700 & 15,65 & \multirow{2}{*}{14,02} & 1,99 & \multirow{2}{*}{1,97} & 3,23 & \multirow{2}{*}{3,93} \\
\hline & 3.000 & 12,38 & & 1,95 & & 4,63 & \\
\hline Média & 2.700 & \multirow{2}{*}{\multicolumn{2}{|c|}{$\begin{array}{l}15,17 \\
13,44\end{array}$}} & \multirow{2}{*}{\multicolumn{2}{|c|}{$\begin{array}{l}1,73 \\
1,65\end{array}$}} & \multicolumn{2}{|c|}{$4,38^{b}$} \\
\hline Mean & 3.000 & & & & & & \\
\hline \multicolumn{2}{|c|}{$\begin{array}{l}\text { Nível de PB } \\
\text { CP level }\end{array}$} & $*$ & & \multicolumn{2}{|c|}{$* *$} & \multicolumn{2}{|c|}{$* *$} \\
\hline \multicolumn{2}{|c|}{$\begin{array}{l}\text { Nível de ED } \\
D E \text { level }\end{array}$} & \multicolumn{2}{|c|}{ NS } & \multicolumn{2}{|c|}{ NS } & \multicolumn{2}{|c|}{$* *$} \\
\hline \multicolumn{2}{|c|}{$\begin{array}{l}\text { Interação } \mathrm{PB} \times \mathrm{ED} \\
C P \times D E \text { interaction }\end{array}$} & \multicolumn{2}{|c|}{ NS } & \multicolumn{2}{|c|}{ NS } & \multicolumn{2}{|c|}{$*$} \\
\hline CV (\%) & & & & & & & \\
\hline
\end{tabular}

valores numéricos, embora não-significativos $(\mathrm{P}>0,05)$, e TEP e ERN médios.

Melhoria na ERN e TEP até determinado nível protéico, acompanhada de diminuição nos níveis subseqüentes, também foi verificada por El-Sayed \& Teshima (1992), com tilápia.

Em alguns casos, no entanto, foi observada elevação da ERN e da TEP quando se reduziu o teor de PB ou se elevou a relação ED:PB da dieta (Parazo, 1990; El-Dahhar \& Lovell, 1995; Santiago \& Reyes, 1991; Hernandez et al., 1995; Vidal Jr., 1995; Furuya et al., 1996; Camargo et al., 1998; Furuya et al., 2000; Fernandes et al., 2000; Sá \& Fracalossi, 2002). Em outros casos, esses parâmetros não foram influenciados pela variação dos níveis protéicos (Sá \& Fracalossi, 2000) ou diminuíram até determinado nível protéico, com elevação nos níveis subseqüentes (Brenner, 1988).
Não houve interação $(\mathrm{P}>0,05)$ dos níveis de $\mathrm{PB} \times$ de ED sobre o NGP, que também não foi afetado pelos níveis de $\mathrm{ED}(\mathrm{P}>0,05)$. A elevação dos níveis de $\mathrm{PB}$ influenciou $(\mathrm{P}<0,01)$ o NGP, que aumentou de forma linear. No entanto, o modelo LRP foi o que melhor se ajustou aos dados, estimando-se em $27,06 \%$ o nível de $\mathrm{PB}$, a partir do qual ocorreu um platô em $1,97 \%$ de NGP.

Para GGP, no entanto, foi observada interação dos níveis de $\mathrm{PB} \times$ de $\mathrm{ED}(\mathrm{P}<0,05)$. Com o desdobramento, tanto para as dietas contendo $2.700 \mathrm{kcal} \mathrm{de}$ $\mathrm{ED} / \mathrm{kg}$ como para aquelas contendo $3.000 \mathrm{kcal}$ de $\mathrm{ED} / \mathrm{kg}$, a elevação dos níveis de $\mathrm{PB}$ influenciou $(\mathrm{P}<0,01) \mathrm{o}$ GGP, que diminuiu de forma linear. No entanto, o modelo LRP foi o que melhor se ajustou aos dados, estimando-se em 26,47 e $28,36 \%$ de PB, a partir dos quais ocorreram os platôs em 3,29\% e 4,63\% de GGP, respectivamente. 
Além disso, os peixes alimentados com as dietas contendo maior nível energético apresentaram maior GGP que aqueles alimentados com as dietas com menor nível energético.

Os valores médios da composição corporal dos peixes estão apresentados na Tabela 4.

Para a composição corporal, não foi verificada interação dos níveis de $\mathrm{PB} \times \mathrm{ED}(\mathrm{P}>0,05)$. Os peixes alimentados com dietas contendo $3.000 \mathrm{kcal}$ de $\mathrm{ED} / \mathrm{kg}$ apresentaram menor teor de umidade $(\mathrm{P}<0,01)$ e maior teor de gordura corporais $(\mathrm{P}<0,01)$ que aqueles que receberam dietas contendo $2.700 \mathrm{kcal}$ de $\mathrm{ED} / \mathrm{kg}$, porém sem diferirem no teor de proteína corporal $(\mathrm{P}>0,05)$.

A elevação dos níveis de PB, contudo, influenciou o teor de gordura $(\mathrm{P}<0,01)$, que diminuiu de forma linear, e os teores de umidade $(\mathrm{P}<0,05)$ e proteína $(\mathrm{P}<0,01)$ corporais, que aumentaram de forma linear.

Estes resultados corroboram os relatos de Garling \& Wilson (1976), Lee \& Putnam (1973), Page \& Andrews (1973), Parazo (1990), Santiago \& Reyes (1991), Hernandez et al. (1995), Fernandes et al. (2000), Sampaio et al. (2000) e Sá \& Fracalossi (2002) de que dietas com maior relação energia:proteína resultaram em maior concentração de lipídios e da taxa de deposição de gordura e em menor concentração de proteína e umidade corporais, o que indica que os peixes alimentados com dietas contendo baixos níveis de proteína provavelmente utilizaram a energia adicional para deposição de gordura.

Observou-se, entretanto, que os peixes alimentados com dietas contendo maior concentração de energia, porém com relação ED/PB inferior à de dietas com menor teor energético, apresentaram maior porcentagem de gordura corporal. Isto se deve, provavelmente, à maior eficiência de deposição da energia excedente oriunda de lipídios, em relação a carboidratos e proteínas, resultando em peixes mais gordos (El Dahhar \& Lovell, 1995; Van Der Meer et al., 1997).

Esses resultados reforçam as observações feitas por Garling \& Wilson (1976) de que, em uma mesma relação energia:proteína, mas com diferentes níveis protéicos e energéticos, os peixes podem diferir em crescimento e composição corporal.

Considerando os resultados obtidos neste estudo para os parâmetros de desempenho e eficiência alimentar, o aumento do teor de lipídios nas dietas com $3.000 \mathrm{kcal}$ de $\mathrm{ED} / \mathrm{kg}$ pode ter promovido efeito "poupador de proteína", semelhante ao que tem sido detectado por vários autores, tanto em espécies car- nívoras como onívoras (Daniels \& Robinson, 1986; Van Der Meer et al., 1997; Lee \& Putnan, 1973; Page \& Andrews, 1973), o que pode ter contribuído para que não fosse observada interação dos níveis de $\mathrm{PB}$ $\times$ ED $(\mathrm{P}>0,05)$ da dieta (respostas similares).

Por outro lado, os resultados obtidos para a composição corporal e as porcentagens de nitrogênio e gordura no ganho de peso demonstraram que o nível de energia contido nas dietas com $2.700 \mathrm{kcal}$ de ED $/ \mathrm{kg}$ não limitou a deposição protéica, tendo em vista que o teor de proteína corporal e a porcentagem de nitrogênio no ganho de peso foram similares em peixes alimentados com ambos os níveis de energia. Contudo, a energia excedente proporcionada pelas dietas contendo $3.000 \mathrm{kcal} \mathrm{de} \mathrm{ED} / \mathrm{kg}$ foi depositada na forma de gordura corporal.

A faixa dos níveis protéicos de uma dieta que proporcionem eficiência de retenção protéica otimizada e máximo ganho de peso indica que, nesse intervalo, taxas de crescimento satisfatórias podem ser alcançadas. Considerando-se a importância do custo das dietas no custo total nos sistemas de produção de peixes, uma dieta que proporcione retenção protéica otimizada (ERN máximo) deveria ser a escolhida (Van Der Meer et al., 1995).

Entretanto, diferentemente do que acontece com a nutrição de animais terrestres, o CRA, como outras variáveis que envolvem o consumo de ração (CAA, a TEP e ERN), não tem sido utilizado como principal critério para se estabelecer a exigência nutricional em experimentos com peixes, em que há dificuldade de mensurar, com precisão, o consumo alimentar dos animais. Em virtude disso, o parâmetro que mais utilizado para estimar a exigência tem sido o ganho de peso (Cowey, 1992, citado por Sá \& Fracalossi, 2002).

Neste caso, apesar de o desempenho ter sido inferior ao observado em algumas espécies do gênero, o nível protéico e/ou a relação ED:PB estimada podem ser considerados adequados para a formulação das dietas para esta espécie. Isso se justifica pelo fato de que cada espécie apresenta uma exigência constante em proteína, dos demais nutrientes (em gramas) e em energia (kcal) para cada grama de ganho de peso. Neste sentido, em condições mais adequadas para o crescimento, em que o animal pode elevar o consumo de ração, as exigências de proteína, de energia e dos demais nutrientes aumentam linearmente a níveis praticamente proporcionais, mantendo o balanceamento estimado neste estudo. 
Tabela 4 - Composição corporal de alevinos de curimbatá e resumo da análise de variância, em função do nível de proteína bruta (PB) e de energia digestível (ED) ${ }^{1}$

Table 4 - Body composition and summary of the analysis of variance, according to different crude protein (CP) and digestible energy (DE) levels fed to curimbatá fingerlings

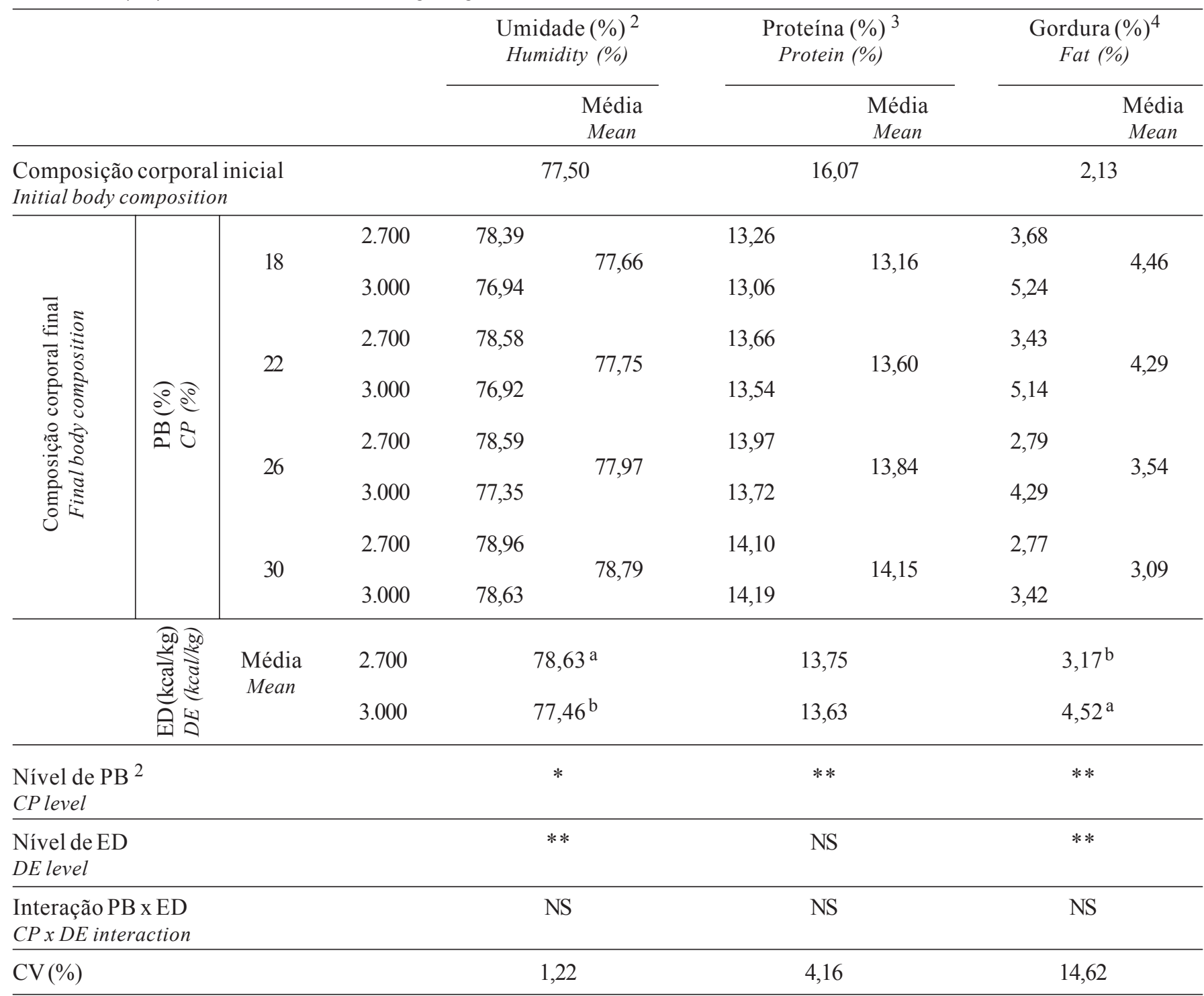

CV- coeficiente de variação (coefficient of variation).

${ }^{*}(P<0,05),{ }^{* *}(P<0,01)$ e ns $(P>0,05)$, pelo teste $F\left[{ }^{*}(P<0.05),{ }^{* *}(P<0.01)\right.$ and $n s(P>0.05)$, by $F$ test.

Médias, na mesma coluna, seguidas de letras diferentes diferem $(P<0,01)$ pelo teste $F$.

Means, in the same column, followed by different letters differ $(P<0.05)$ by $F$ test.

${ }^{1}$ Matéria natural (Natural matter).

2 Efeito linear (Linear effect): $\hat{Y}=75,8741+0,0904 X\left(r^{2}=0,82\right)$.

3 Efeito linear (Linear effect): $\hat{Y}=12,8862+0,3204 X\left(r^{2}=0,98\right)$.

${ }^{4}$ Efeito linear (Linear effect): $\hat{Y}=6,7531-0,1212 X\left(r^{2}=0,95\right)$.

\section{Conclusões}

As exigências de proteína bruta e energia digestível para alevinos de curimbatá são de $26,05 \%$ de PB e $2.700 \mathrm{kcal} \mathrm{de} \mathrm{ED} / \mathrm{kg}$, que correspondem à relação energia digestível:proteína bruta de 10,36 kcal de ED/g de $\mathrm{PB}$, por proporcionarem as melhores respostas em ganho de peso e composição de carcaça.

\section{Literatura Citada}

BARBOSA, N.D.C. Efeito do teor de proteína na ração e da adubação dos tanques de curimbatá (Prochilodus scrofa STEINDACHNER, 1881). Belo Horizonte: Universidade Federal de Minas Gerais, 1987. 52p. Dissertação (Mestrado em Zootecnia) - Universidade Federal de Minas Gerais, 1987.

BOISCHIO, A.A.P. Produção pesqueira em Porto Velho, Rondônia (1984-89) - alguns aspectos ecológicos das espé- 
cies comercialmente relevantes. Acta Amazonica, v.22, n.1, p.163-172, 1992.

BOWEN, S.H. Dietary protein requirements of fish - A reassessment. Canadian Journal of Fisheries and Aquatic Sciences, v.44, n.11, p.1995-2001, 1987.

BRENNER, M. Determinação da exigência de proteína do pacu (Colossoma mitrei BERG, 1895). Viçosa, MG: Universidade Federal de Viçosa, 1988. 87p. Dissertação (Mestrado em Zootecnia) - Universidade Federal de Viçosa, 1988.

CAMARGO, A.C.S.; VIDAL JR., M.V.; DONZELE, J.L. et al. Níveis de energia metabolizável para tambaqui (Colossoma macropomum) dos 30 aos 180 gramas de peso vivo. 1. Composição das carcaças. Revista Brasileira de Zootecnia, v.27, n.3, p.409-415, 1998.

CERDEIRA, R.G.P.; RUFFINO, M.L.; ISAAC, V.J. Consumo de pescado e outros alimentos pela população ribeirinha do Lago Grande de Monte Alegre, PA - Brasil. Acta Amazonica, v.27, n.3, p.213-228, 1997.

COWEY, C.B.; WALTON, M.J. Intermediary metabolism. In: HALVER, J. (Ed.) Fish nutrition. 2.ed. Washington: Academic Press, 1989. p.1-29.

COWEY, C.B. Nutrition: estimating requirements of rainbow trout. Aquaculture, v.100, p.117-189, 1992.

DANIELS, W.H.; ROBINSON, E.H. Protein and energy requirements of juvenile red drum (Sciaenops ocellatus). Aquaculture, v.53, p.243-252, 1986.

El-DAHHAR, A.A.; LOVELL, R.T. Effect of protein to energy ratio in purified diets on growth performance, feed utilization and body composition of mossambique tilapia, Oreochromis mossambicus (Peters). Aquaculture Research, v.26, p.451-457, 1995.

El-SAYED, A.M.; TESHIMA, S. Protein and energy of nile tilapia, Oreochromis niloticus, fry. Aquaculture, v.103, p.55-63, 1992.

FERNANDES, J.B.K.; CARNEIRO, D.J.; SAKOMURA, N.K. Fontes e níveis de proteína bruta em dietas para alevinos de pacu, Piaractus mesopotamicus). Revista Brasileira de Zootecnia., v.29, n.3, p.646-653, 2000.

FURUYA, W.M.; HAYASHI, C.; FURUYA, V.R.B et al. Exigência de proteína para machos revertidos de tilápia do nilo (Oreochromis niloticus) na fase juvenil. Revista UNIMAR, v.18, n.2, p.307-319, 1996.

FURUYA, V.R.B.; HAYASHI, C.; FURUYA, W.M. et al. Influência de plâncton, dieta artificial e sua combinação, sobre o crescimento, sobrevivência de larvas de curimbatá (Prochilodus lineatus). Acta Scientiarum, v.21, n.3, p.699703, 1999.

FURUYA, W.M.; HAYASHI, C.; FURUYA, V.R.B. et al. Exigência de proteína para alevino revertido de tilápia do nilo (Oreochromis niloticus). Revista Brasileira de Zootecnia, v.29, n.6, p.1912-1917, 2000.

GARLING, D.L.; WILSON, R.P. Optimum dietary protein to energy ratio for channel catfish, Ictalurus punctatus. Journal Nutrition, v.106, p.1368-1375, 1976.

GALDIOLI, E.M.; HAYASHI, C.; SOARES, C.M. et al. Diferentes fontes protéicas na alimentação de alevinos de curimba (Prochilodus lineatus V.). Acta Scientiarum, v.22, n.2, p.471-477, 2000.

GALDIOLI, E.M.; HAYASHI, C.; SOARES, C.M. et al. Substituição da proteína do farelo de soja pela proteína do farelo de canola em rações para alevinos de curimbatá (Prochilodus lineatus V.). Revista Brasileira de Zootecnia, v.31, n.2, p.552-559, 2002.
HAYASHI, C.; GALDIOLI, E.M.; NAGAE, M.Y. et al. Exigência de proteína para alevinos de Lambari (Astyanax bimaculatus) (Pisces: Characidae). In: REUNIÃO ANUAL DA SOCIEDADE BRASILEIRA DE ZOOTECNIA, 36. 1999, Porto Alegre. Anais... São Paulo: Gmosis, 1999. CD-ROM. Pequenos animais. PEQ-024.

HERNANDEZ, M.; TAKEUCHI, T.; WATANABE, T. Effect of dietary energy sources on the utilization of protein by Colossoma macropomum fingerlings. Fisheries Science, v.61, n.3, p.507-511, 1995.

LEE, D.J.; PUTNAM, G.B. The response of rainbow trout to varying protein/energy ratios in a test diet. Journal Nutrition, v.103, p.916-922, 1973.

LEITE, R.G.; VERANI, J.R.; CESTAROLLI, M.A. et al. Estudos biométricos do curimbatã, Prochilodus scrofa, em experimento de cultivo com suplementação alimentar (II) - crescimento. In: SIMPÓSIO BRASILEIRO DE AQÜICULTURA, 3., 1984, São Carlos. Anais... São Carlos: Associação Brasileira de Aquicultura, 1984. p.345-363.

NATIONAL RESEARCH COUNCIL - NRC. Nutrient requirements of warmwater fishes and shellfishers. Washington, D.C.: National Academy of Science, 1983. 102p.

NATIONAL RESEARCH COUNCIL - NRC. Nutrient requirements of fish. Washington, D.C.: National Academy of Science, 1993. 105p.

PAGE, J.W.; ANDREWS, J.W. Interactions of dietary levels of protein and energy on channel catfish (Ictalurus punctatus). Journal Nutrition, n.103, p.1339-1346, 1973.

PAIXÃO, A.M.S. Avaliação de ração peletizada e não peletizada na engorda de híbridos de curimbatás $\widehat{O}^{\circ}$ de Prochilodus marggravii $\mathrm{x} Q$ de $P$. affinis. In: COLETÂNEA DE RESUMOS DOS ENCONTROS DA ASSOCIAÇÃO MINEIRA DE AQÜICULTURA, 1988, Brasília. Resumos... Brasília: Associação Brasileira de Aquicultura, 1988. p.119.

PAIXÃO, A.M.S.; HANCZ, C. Adubação orgânica em viveiros associados à ração na engorda de curimbatás (Prochilodus marggravii). Revista da Sociedade Brasileira de Zootecnia, v.18, n.6, p.500-513, 1989.

PARAZO, M.M. Effect of dietary protein and energy level on growth, protein utilization and carcass composition of rabbitfish, Siganus guttatus. Aquaculture, v.86, p.41-49, 1990.

PEZZATO, L.E.; BARROS, M.M.; PEZZATO, A.C. et al. Relación energia/proteína en la nutrición de alevinos de piauçú (Leporinus macrocephalus). Revista de Medicina Veterinária y Zootecnia, v.1, p.2-6, 2000.

PINTO, C.S.R.M.; De PAIVA, P.; ANTONIUTTI, D.M. et al. Influência do arraçoamento no crescimento do curimbatã, Prochilodus scrofa, em tanques experimentais de cultivo. In: SIMPÓSIO BRASILEIRO DE AQÜICULTURA, 3., 1984, São Carlos. Anais... São Carlos: Associação Brasileira de Aquicultura, 1984. p.313-327.

ROSTAGNO, R.S.; ALBINO, L.F.T.; DONZELE, J.L. et al. Tabelas brasileiras para aves e suínos - composição de alimentos e exigências nutricionais. 2.ed. Viçosa, MG: Universidade Federal de Viçosa, 2000. 141p.

SÁ, M.V.C.; FRACALOSSI, D.M. Exigência protéica e relação energia/proteína para alevinos de piracanjuba (Brycon orbigyanus). Revista Brasileira de Zootecnia, v.31, n.1, p.1-10, 2002.

SAMPAIO, A.M.B.; KUBITZA, F.; CYRINO, J.E.P. Relação energia:proteína na nutrição do tucunaré. Scientia Agrícola, v.57, n.2, p.213-219, 2000. 
SANTIAGO, C.B.; REYES, O.F. Optimum dietary protein level for growth of bighead carp (Aristichthys nobilis) fry in a static water system. Aquaculture, v.93, p.155-165, 1991.

SIDDIQUI, A.Q.; HOWLADER, M.S.; ADAM, A.A. Effects of dietary protein levels and protein utilization in fry and young nile tilapia, Oreochromis niloticus. Aquaculture, v.70, p.6373, 1988.

SILVA, D.J. Análise de alimentos (métodos químicos e biológicos). 2.ed. Viçosa, MG: Universidade Federal de Viçosa, 1990. 165 p.

UNIVERSIDADE FEDERAL DE VIÇOSA - UFV. Central de processamento de dados UFV/CPD. Manual de utilização do programa SAEG (Sistema para análises estatísticas e genéticas). Viçosa, MG: Universidade Federal de Viçosa, 1993. 59p.

van der MEER, M.B.; MACHIELS, M.A.M.; VERDEGEM, M.C.J. The effect of dietary protein level on growth, protein utilization and body composition of Colossoma macropomum (Cuvier). Aquaculture Research, v.26, p.901-909, 1995.

van der MEER, M.B.; ZAMORA, J.E.; VERDEGEM, M.C.J. Effect of dietary lipid level on protein utilization and the size and proximate composition of body compartments of Colossoma macropomum (Cuvier). Aquaculture Research, v.26, p.405-417, 1997.

VIDAL JR., M.V. Níveis de proteína bruta para tambaqui (Colossoma macropomum) dos 30 aos $250 \mathrm{~g}$ de peso vivo. Viçosa, MG: Universidade Federal de Viçosa, 1995. 49p. Dissertação (Mestrado em Zootecnia) - Universidade Federal de Viçosa, 1995.

WINFREE, R.A.; STICKNEY, R.R. Started diets for channel catfish: effects of dietary protein on growth and carcass composition. The Progressive Fish-Culturist, v.46, n.2, p.79-86, 1984.

YOSSA, M.I.; ARAÚJO-LIMA, A.R.M. Detritivory in two amazonian fish species. Journal of Fish Biology, v.52, p.1141-1153, 1998 .

Recebido em: 26/06/04

Aceito em: 08/06/05 